\title{
Effect of doxycycline concentrations in chicken tissues as a consequence of permanent exposure to enrofloxacin traces in drinking water
}

\author{
Małgorzata Gbylik-Sikorska ${ }^{1}$, Andrzej Posyniak ${ }^{1}$, Tomasz Śniegocki ${ }^{1}$, Bartosz Sell ${ }^{1}$, \\ Anna Gajda ${ }^{1}$, Grzegorz Tomczyk ${ }^{2}$, Jan Żmudzki ${ }^{1}$ \\ ${ }^{1}$ Department of Pharmacology and Toxicology \\ ${ }^{2}$ Department of Poultry Diseases \\ National Veterinary Research Institute, 24-100 Pulawy, Poland \\ malgorzata.gbylik@piwet.pulawy.pl
}

Received: June 21, 2016

Accepted: September 5, 2016

\begin{abstract}
Introduction: The main problem in poultry farming is the difficulty in producing food of animal origin without using antibacterial agents. Because most antibacterial compounds are dispensed in water, some water supply systems can be contaminated by antibiotics which are then administered to the animals unintentionally. This can lead to unexpected increases in antibiotic residues in food of animal origin. The aim of the present study was to determine whether the constant exposure of chicken broilers to enrofloxacin affects the withdrawal time of a therapeutic doxycycline that is intentionally administered to the chickens. Material and Methods: The concentrations of doxycycline, enrofloxacin, and ciprofloxacin were determined by LC-MS/MS in muscles and liver of the chickens. Results: Doxycycline residue concentrations in the chicken tissues from the group that received trace amounts of enrofloxacin were nearly $50 \%$ greater than those of the group that received only doxycycline. Conclusion: These results indicated that constant exposure to enrofloxacin in trace amounts significantly influences the residual doxycycline concentration in chicken tissues.
\end{abstract}

Keywords: chickens, doxycycline, enrofloxacin, drinking water, LC-MS/MS.

\section{Introduction}

In accordance with the European Union Report which presented the medium-term outlook for the major EU agricultural commodity markets and agricultural income until 2024, poultry is the only meat for which both consumption and production are steadily increasing. Between 2014 and 2024, a 7\% increase in poultry production is expected. Poland is one of the four major poultry producers that together accounted for $44 \%$ of the total EU production in 2013. Moreover, a $1 \%$ increase in production per year has been predicted. The total EU production is expected to reach nearly 14 million tonnes by 2024 (13). Largescale production is associated with great responsibility and the need for best practices to maintain meat quality. The grouping of a large number of animals in a small space is a factor which facilitates the rapid spread of bacterial infections in farm environments $(5,21,22)$. Despite the use of various treatment protocols designed to improve animal welfare and the animals' subsequent resistance, antimicrobial substances ultimately remain the most effective for mitigating the losses caused by infections (21).

One of the most practical and economical routes of administration of veterinary drugs for chickens is drinking water. It offers low solution preparation cost, easy distribution and storage, fast administration to all birds in the early stages of disease, and quick dose or drug change (22). However, this method of administration has a few disadvantages which are associated with water quality (requiring it to be pure and have neutral $\mathrm{pH}$ and suitable hardness level), water hygiene (in that it must be clean, disinfected, and descaled), and the physicochemical properties of drugs (their solubility in water, adsorption in the solid phase, 
and formation of complexes with ions present in drinking water). These variables have huge impact on the practitioner's attempt to ensure proper application of drugs. Inadequate hygiene in water supply systems may produce undesirable effects such as antibiotic contamination of dispensers and application containers and trace intake by untreated chickens. It is therefore important to introduce a system of regular sanitation procedures in water supply systems using special cleaners, especially after the end of antibiotic treatment. However, due to the short breeding time of broiler chickens and repeated attempts to treat infections using various antibacterial agent interactions may take place, which often occur specifically after oral drug administration. Such interactions may disorder therapy and drug elimination from tissue, and can significantly deteriorate the quality of food products of animal origin. Undesirable interactions can increase the occurrence of antibacterial agent residues in food products, which may threaten the health of consumers (by raising antibiotic resistance, triggering allergies, or causing disorders of the digestive tract or even the entire organism) $(1,4,5,18)$. To protect consumer health, the European Union has set maximum residue limits (MRLs) for veterinary substance residues which can be dangerous to human health (7). The results of pilot studies have provided information about the presence of antibacterial agents in water samples from the water supply systems of breeding animal farms. In 50 tested water samples collected from likely unclean dispensers in poultry farms, 38\% of the samples contained enrofloxacin in the range of $1.6 \mu \mathrm{g} / \mathrm{L}$ to $1650 \mu \mathrm{g} / \mathrm{L}(17)$.

The pharmacodynamic properties (mechanisms and scopes) of antimicrobial agents, such as enrofloxacin and doxycycline, are such that they are among the most commonly used agents to treat infections in poultry. Enrofloxacin belongs to the most effective group of synthetic antibiotics, the fluoroquinolones. The USA, Denmark, and Finland have banned the use of fluoroquinolones in poultry treatment. However the majority of countries in the European Union, including Poland, still allow their use due to their broad spectra of activity and high efficiency against Gram-positive and Gram-negative bacteria. The antibiotic action is based on DNA gyrase, which is an essential bacterial enzyme that maintains the superhelical twists of the DNA (3, 30, 35). Doxycycline also exhibits strong activity against a broad range of bacteria; its action is based on the inhibition of protein biosynthesis in the bacterial cell $(9,19)$. In poultry treatment, both of these medicines are generally administered in drinking water, and this administration route provides a relatively rapid therapeutic effect. However, the physicochemical properties of enrofloxacin and doxycycline allow them to remain in dispensers. Missed intervals in sanitising the water lines with special cleaners, particularly after finishing a course of antibiotic administration, can lead to traces of antibiotics being constantly administered to chickens which do not require treatment $(8,14,15)$. Chronic exposure to traces of chemotherapeutics and antibiotics may interfere with the actions of other drugs that are intentionally administered for the treatment of animal infections. Although there have been studies of antibacterial compounds including doxycycline residue concentrations in different animal tissues $(8,11,14,15$, $20,26,31,32,34)$, there is no information about the possible effects of constant exposure to trace amounts of previously used antibiotics on target antibiotics in chicken tissue. Therefore, this study elucidates the effects of constant trace amounts exposure on the residues of intentionally applied doxycycline in chicken breast, thigh, and liver.

\section{Material and Methods}

Animals and dosing. The experiments were performed on 24 one-day-old Lohmann broiler chickens (non-sexed). The broilers were maintained in the vivarium of the National Veterinary Research Institute in Pulawy, Poland. The chickens were placed in cages with free ad libitum access to water and antibiotic-free feed. The rooms were air-conditioned and the temperature was gradually decreased from $36^{\circ} \mathrm{C}$ on the first day to $23^{\circ} \mathrm{C}$ by the third week of life. The humidity was regulated on a "day-night" cycle. The animals were divided into two experimental groups, as illustrated in Fig. 1.

In group I $(n=12)$, which served as the positive control, each bird received antibiotic-free water and feed ad libitum until the end of the experiment. In the fifth week of the chickens' lives, a veterinary drug containing doxycycline (doxycycline hyclate $500 \mathrm{mg} / \mathrm{g}$, oral powder, 6-day withdrawal time (WT)) was administered at a dose of $20 \mathrm{mg} / \mathrm{kg} \quad \mathrm{b} . \mathrm{w}$. for five consecutive days.

In group II $(\mathrm{n}=12)$, the birds received enrofloxacin via drinking water from the second day of life until the end of the experiment. A water solution containing $500 \mu \mathrm{g} / \mathrm{L}$ of enrofloxacin was prepared by the dilution of enrofloxacin standard solution in drinking water on each morning. The enrofloxacin dose was selected based on the results of a previous pilot study (9). Enrofloxacin was the most detected compound in the water samples collected from the water supply systems during the pilot study, when its concentration was approximately $500 \mu \mathrm{g} / \mathrm{L}$. In the fifth week of the presented experiment, the administration of doxycycline according to the same protocol as for group I was begun. Tissue samples (breast muscle, thigh muscle, and liver) were collected on the fifth and sixth days of WT and one day after WT ( $n=4$ for each time point in all groups). All samples were kept at $-20^{\circ} \mathrm{C}$ until LC-MS/MS analysis for the determination of doxycycline (groups I and II), enrofloxacin, and ciprofloxacin (group II). 


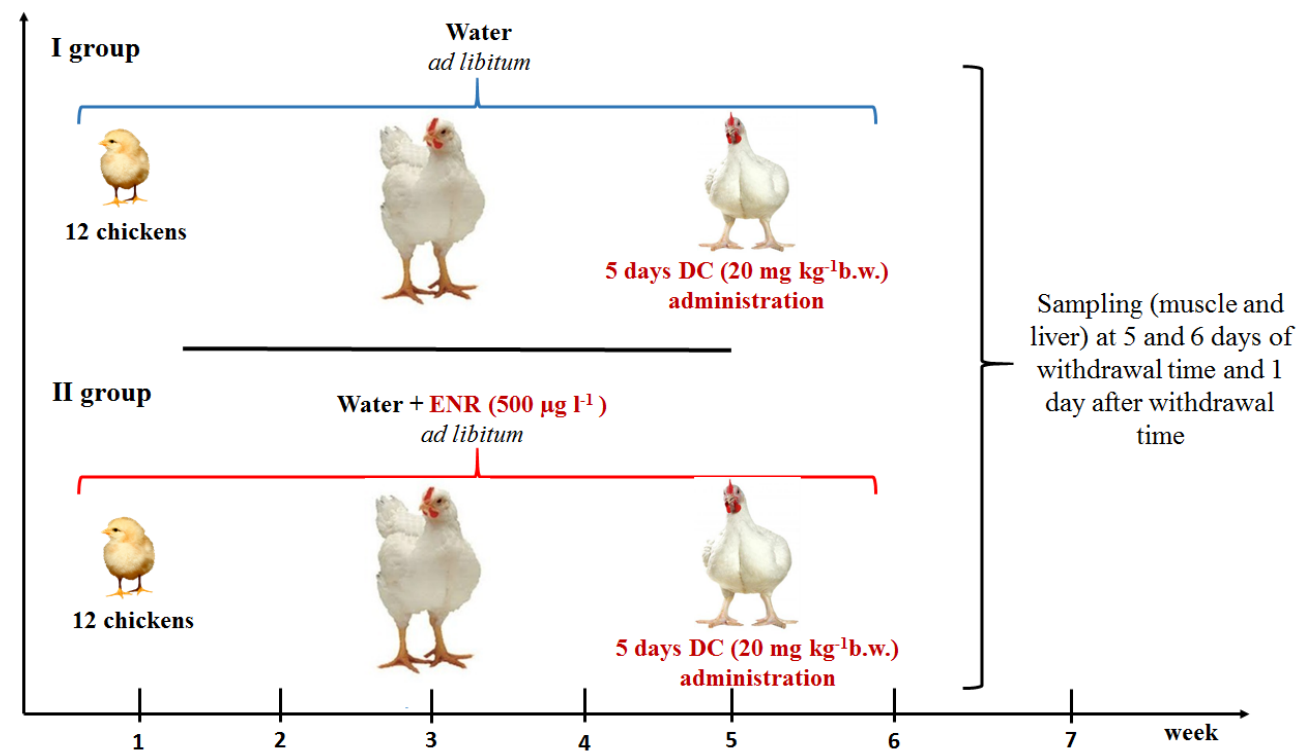

Fig. 1. The scheme of the experiment

Reagents and chemicals. All reagents used were of analytical grade $>95 \%$ purity. Formic acid, sodium hydroxide, and $98 \%$ ethanol were obtained from $\mathrm{POCH}$ (Poland). Acetonitrile, ethyl acetate, and methanol were sourced from J.T. Baker (the Netherlands), and trichloroacetic acid (TCA) was procured from SigmaAldrich (USA). Syringe filters $(0.22 \mu \mathrm{m})$ were chosen from Restek (USA) in PVDF variety, and from Millipore (USA) in PTFE material. The water was deionised $\left(>18 \mathrm{MX} \mathrm{cm}^{-1}\right)$ using a Millipore system. Doxycycline, oxytetracycline, enrofloxacin, ciprofloxacin, and ciprofloxacin- $\mathrm{d}_{8}$ were bought from Sigma-Aldrich (USA).

Standard solution. Individual stock standard solutions $(1 \mathrm{mg} / \mathrm{mL})$ of doxycycline were prepared in methanol in amber volumetric flasks and stored at $-18^{\circ} \mathrm{C}$. Enrofloxacin and ciprofloxacin were prepared in methanol with the addition of $0.1 \%$ sodium hydroxide (9:1, v:v) and also stored at $-18^{\circ} \mathrm{C}$ and the same storage condition was given to the stock standard enrofloxacin solution which was prepared in ethanol. The mixtures of the working standard solutions were prepared in deionised water in amber glass and stored at $4{ }^{\circ} \mathrm{C}$. Individual stock internal standard (IS) solutions (1 mg/mL) of oxytetracycline (IS 1) and ciprofloxacin$\mathrm{d}_{8}$ (IS 2) were likewise prepared in deionised water in amber volumetric flasks and stored at $-18^{\circ} \mathrm{C}$. The mixtures of the working internal standards received the same preparation and were stored at $4^{\circ} \mathrm{C}$.

\section{Analytical methods}

Extraction and clean up. A $2 \pm 0.05$ g sample of homogenous tissues (breast muscle, thigh muscle, and liver) was weighed in a $50 \mathrm{~mL}$ centrifuge tube, and $50 \mu \mathrm{L}$ of IS mixture was added. The sample was mixed and left to incubate at $4^{\circ} \mathrm{C}$ in the dark for $30 \mathrm{~min}$. After adding $100 \mu \mathrm{L}$ of $20 \%$ TCA, $6 \mathrm{~mL}$ of $0.5 \%$ formic acid in acetonitrile and ethyl acetate (1:1, v:v) was added, and the sample was homogenised with a vortex mixer for 1 min and then mixed well with a mechanical mixer for $15 \mathrm{~min}$. The sample was then centrifuged at $2930 \times \operatorname{rcf}$ for $10 \mathrm{~min}$ at $4^{\circ} \mathrm{C}$. Three millilitres of the supernatant was collected and filtered through a $0.22 \mu \mathrm{m}$ PTFE syringe filter into a glass tube. The sample was then evaporated to dryness under a stream of nitrogen at $45 \pm 5^{\circ} \mathrm{C}$. The residue was dissolved in $500 \mu \mathrm{L}$ of $0.1 \%$ formic acid and filtered through a $0.22 \mu \mathrm{m}$ PVDF syringe filter into an LC vial.

Liquid chromatography-mass spectrometry. The LC-MS/MS analysis was performed on an Agilent 1200 HPLC system (Agilent Technologies, Germany) coupled with an AB Sciex QTRAP ${ }^{\circledR} 6500$ triple quadrupole mass spectrometer (AB Sciex, USA). Electrospray ionisation was performed in the positive mode with the following parameters: temperature $450^{\circ} \mathrm{C}$; ion spray voltage $5500 \mathrm{~V}$; nebuliser gas $\left(\mathrm{N}_{2}\right)$ 35; curtain gas $\left(\mathrm{N}_{2}\right) 20$; collision gas $\left(\mathrm{N}_{2}\right) 16$; and auxiliary gas 16 . Data acquisition was performed in multiple-reaction monitoring (MRM) mode. The mass parameters and ion transitions which were monitored for the analytes are listed in Table 1. The chromatographic separation was performed on a Luna C18(2) 100 A column of $50 \times 2.0 \mathrm{~mm}$, particle size $3 \mu \mathrm{m}$ (Phenomenex, USA), connected to a C18 precolumn of $4.0 \mathrm{~mm} \times 2.0 \mathrm{~mm} \times 2 \mu \mathrm{m}$ (Phenomenex) which was maintained at $35^{\circ} \mathrm{C}$. The mobile phase consisted of solvent A: $0.1 \%$ formic acid in acetonitrile; and solvent B: $0.1 \%$ formic acid. The gradient programme started at $95 \% \mathrm{~B}$, decreased to $60 \%$ at $3.0 \mathrm{~min}$, and to $20 \%$ at $3.01 \mathrm{~min}$, where it was held for $2.30 \mathrm{~min}$. The mobile phase returned to the initial composition at $5.31 \mathrm{~min}$ and was equilibrated for another $3.30 \mathrm{~min}$ before the next injection. The LC flow was maintained at $500 \mu \mathrm{L} / \mathrm{min}$, and the injection 
volume was $5 \mu \mathrm{L}$. The LC-MS/MS system was controlled by Analyst 1.6.2 software (AB Sciex) and this was also used to process the data.

Validation. The method was validated according to the requirements of European Commission Decision 2002/657/EC (6). Antibiotic-free muscle and liver samples were used for the validation process. The IS mixture $(50 \mu \mathrm{L})$ was added to each sample, and the samples were fortified with a $50 \mu \mathrm{L}, 100 \mu \mathrm{L}$, or $150 \mu \mathrm{L}$ mixture of standard solution to reach concentrations of $0.5,1.0$, or $1.5 \mathrm{MRL}$ respectively. The matrix-matched calibration curve was prepared by fortifying blank tissue samples at six concentrations $(10,50,100,250$, 500,1000 , and $2000 \mu \mathrm{g} / \mathrm{kg}$ ). The quantitative results were evaluated by comparing the analyte/internal standard peak area ratios based on the matrix-matched calibration curve to the analyte/internal standard peak area ratios of the analysed samples. A repeatability experiment was performed by analysing six identical spiked samples at $0.5,1.0$ and 1.5 times the MRL for each analyte. The samples were analysed with the same instrument on the same day and by the same operators. The within-laboratory reproducibility was determined after fortifying two further sets of blank samples at the same concentrations of the analysed compounds and performing the analyses with the same instrument on two different days and with different operators. The repeatability and within-laboratory reproducibility were evaluated by calculating the coefficients of variation $(\mathrm{CVs}, \%)$. The percentage recoveries (relative to the internal standard) were evaluated in the same way as the repeatability experiment by comparing the mean measured concentrations with the fortified concentrations of the samples. The decision limit
$(\mathrm{CC} \alpha)$ and detection capability $(\mathrm{CC} \beta)$ were determined using the matrix-matched calibration curve procedure.

Statistical analysis. The differences in the mean concentrations of doxycycline in the tissues between the two groups with respect to days of sample collection were statistically evaluated. A computerbased-version of the $t$-test was used for the analyses (Prism v 5.0.4, build 533; GraphPad Software, Inc., USA) with a significance level of $\mathrm{P}<0.05$.

\section{Results}

The method used for the tissue analysis performed well during the analytical phase of the study. The $0.5 \%$ formic acid in a mixture of acetonitrile and ethyl acetate with the addition of $20 \%$ TCA gave good results because of the extraction solvent and allowed the best results to be achieved (the best recoveries for all analytes). The double filtration (filtration of the supernatant through the PTFE syringe filter and filtration of the reconstituted residue through the PVDF equivalent) achieved the best reduction of the interfering components and improved the purification of the final extracts for all matrices. The presented method was thoroughly validated, and the results are reported in Table 2. For all matrices, all coefficients of determinations were always $\geq 0.99$. All analytes produced acceptable results that met the criteria of the European Commission Decision 2002/657/EC (6).

Throughout the study, all birds were clinically healthy, and no adverse events were observed. The mean tissue concentrations $( \pm \mathrm{SD})$ of doxycycline in the chickens are illustrated in Fig. 2.

Table 1. MS ion transitions and parameters

\begin{tabular}{|c|c|c|c|c|c|}
\hline Analyte & Ion transition $1(\mathrm{~m} / \mathrm{z})$ & Ion transition $2(\mathrm{~m} / \mathrm{z})$ & $\mathrm{DP}(\mathrm{V})$ & $\mathrm{CE}(\mathrm{Ev})$ & Dwell time (ms) \\
\hline Doxycycline & $445.0 / 428.0$ & $445.0 / 154.0$ & 55 & 34 & 20 \\
\hline Enrofloxacin & $360.0 / 342.0$ & $360.0 / 286.0$ & 60 & 35 & 20 \\
\hline Ciprofloxacin & $332.0 / 314.0$ & $332.0 / 231.0$ & 60 & 30 & 20 \\
\hline Oxytetracycline (IS1) & $461.0 / 426.0$ & - & 40 & 30 & 20 \\
\hline Ciprofloxacin-d (IS2) & $340.0 / 322.0$ & - & 40 & 29 & 20 \\
\hline
\end{tabular}

Table 2. Validation parameters for the LC-MS/MS method for the determination of doxycycline, enrofloxacin, and ciprofloxacin in tissues

\begin{tabular}{|c|c|c|c|c|c|c|c|}
\hline Analyte & Matrix & $\begin{array}{l}\text { MRL } \\
(\mu g / k g)\end{array}$ & $\begin{array}{l}\text { Repeatability, } \\
\text { CV (\%) }\end{array}$ & $\begin{array}{l}\text { Within-laboratory } \\
\text { reproducibility, CV (\%) }\end{array}$ & $\mathrm{CC} \alpha(\mu \mathrm{g} / \mathrm{kg})$ & $\mathrm{CC} \beta(\mu \mathrm{g} / \mathrm{kg})$ & Recovery (\%) \\
\hline \multirow{2}{*}{ Doxycycline } & muscle & 100 & 2.1 & 5.2 & 103 & 115 & 98.5 \\
\hline & liver & 300 & 3.6 & 6.4 & 312 & 334 & 108 \\
\hline \multirow{2}{*}{ Enrofloxacin } & muscle & 100 & 2.0 & 4.7 & 106 & 117 & 106 \\
\hline & liver & 200 & 3.3 & 5.2 & 209 & 227 & 110 \\
\hline \multirow{2}{*}{ Ciprofloxacin } & muscle & 100 & 2.7 & 4.9 & 105 & 119 & 93 \\
\hline & liver & 200 & 3.4 & 6.1 & 214 & 230 & 98 \\
\hline
\end{tabular}




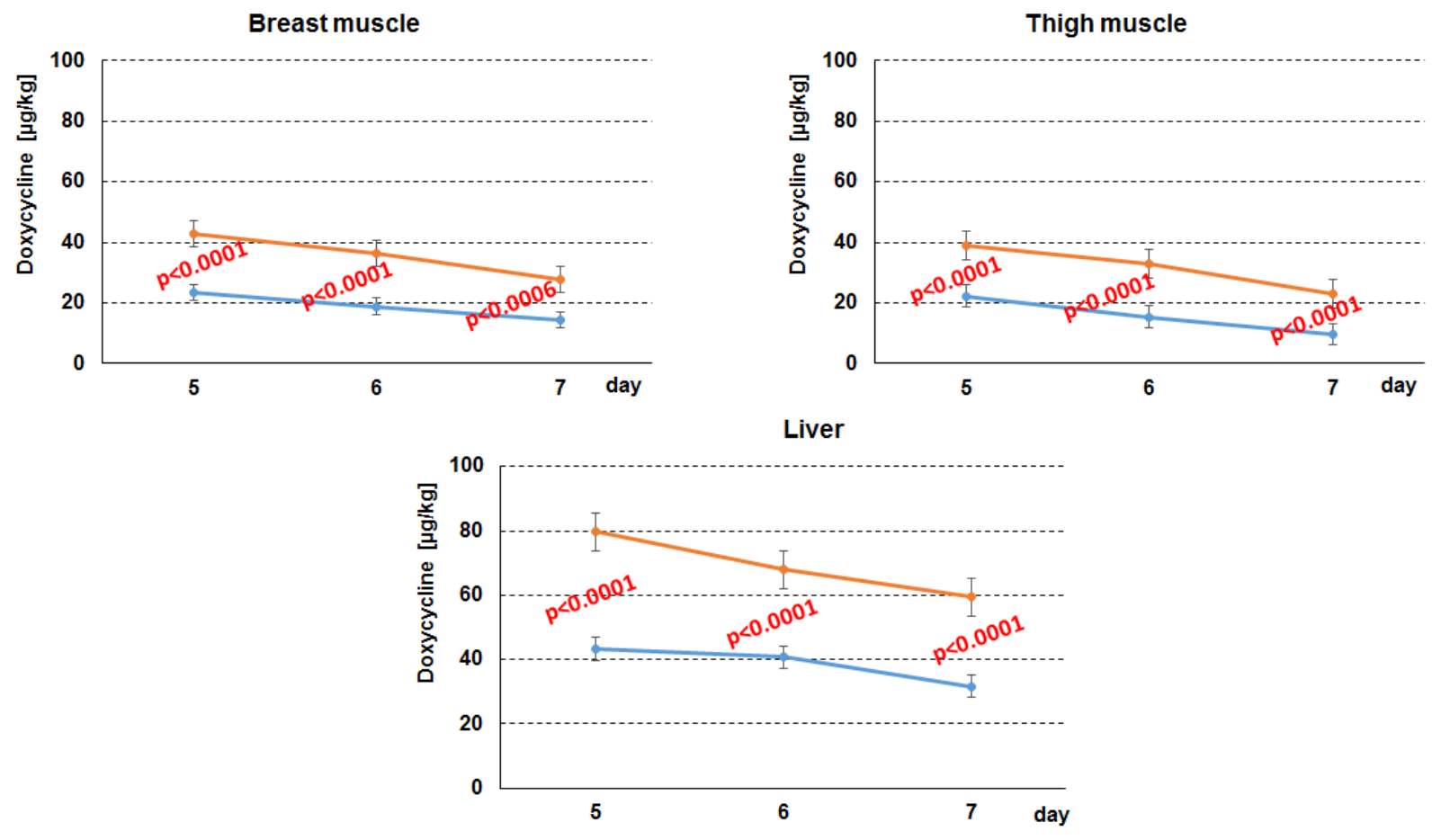

Fig. 2. Comparison of doxycycline residue concentration in broiler chickens tissue for both experimental groups ( - group I, - group II)

The doxycycline residue concentrations in group I ranged from $23.55 \pm 6.8$ to $14.32 \pm 5.8 \mu \mathrm{g} / \mathrm{kg}$ (breast muscles), from $22.22 \pm 8.2$ to $12.67 \pm 5.2 \mu \mathrm{g} / \mathrm{kg}$ (thigh muscles), and from $48.37 \pm 12.1$ to $36.72 \pm 17.8 \mu \mathrm{g} / \mathrm{kg}$ (liver), over days five to seven. In the tissues collected from the birds which consumed enrofloxacin in water (group II), the doxycycline residue concentrations were almost $50 \%$ higher than those in group I and ranged from $42.75 \pm 14.8$ to $27.77 \pm 11.8 \mu \mathrm{g} / \mathrm{kg}$ (breast muscles), from $38.97 \pm 14.6 \mu \mathrm{g} / \mathrm{kg}$ to $22.92 \pm 13.8$ (thigh muscles), and from $79.67 \pm 13.1$ to $59.37 \pm$ $19.8 \mu \mathrm{g} / \mathrm{kg}$ (liver). After constant exposure of the birds of group II to trace enrofloxacin $(500 \mu \mathrm{g} / \mathrm{l})$ over the three consecutive days, enrofloxacin residue concentrations were $13.15 \pm 6.8 \mu \mathrm{g} / \mathrm{kg}$ in the breast muscle, $11.35 \pm 4.3 \mu \mathrm{g} / \mathrm{kg}$ in the thigh muscle, and $39.85 \pm 15.2 \mu \mathrm{g} / \mathrm{kg}$ in the liver. The ciprofloxacin residues were detected only in the liver, and the observed concentration was $20.35 \pm 7.6 \mu \mathrm{g} / \mathrm{kg}$.

The difference in the doxycycline residue concentrations between the tissues of group I, which received only doxycycline at a therapeutic dose, and those of group II, which received the same dose of doxycycline during constant exposure to trace amounts of enrofloxacin in the drinking water, was significant $(\mathrm{P}<0.05)$. The results are illustrated in Fig. 2.

\section{Discussion}

In the presented study, the potential influence of constant exposure to trace amounts of enrofloxacin in the drinking water on doxycycline residues in chicken tissues was clarified. The research attracted interest because this situation occurs frequently on poultry farms. The need for this experiment was to fill a knowledge gap regarding the potential influence of the unintentional and subtherapeutic administration of enrofloxacin in drinking water on intentionally administered doxycycline in chicken broilers. Our previous study demonstrated that there was enrofloxacin residue content in some drinking water samples taken from dispensers on poultry farms which were probably not sanitised with specialised cleaners. Additionally, data collected for the last three years by the Rapid Alert System for Food and Feed indicate that the doxycycline residue concentrations exceeded the acceptable standards (MRL) in various poultry products (10 cases) (27).

The development of a rapid and appropriate analytical method was needed to determine the doxycycline, enrofloxacin, and ciprofloxacin tissue concentrations. The optimisations of instrumental parameters and sample preparation procedures were based on the available literature $(8,10,14,15,29)$ and our experience with antibiotic residue analyses $(4,16)$. The developed method provided quantitative doxycycline, enrofloxacin, and ciprofloxacin determination results.

In both groups, doxycycline residues were present in all analysed tissues on the fifth and sixth days of WT and on the first day after WT. Previous studies $(11,15)$ have reported that doxycycline residues are still present in chicken tissues five days after oral administration, and the concentrations are dependent on the applied doses. No significant differences were 
found between the doxycycline concentrations in the breast and thigh muscles. The highest doxycycline concentration was observed in the liver, and similar results have previously been reported by other authors $(2,11,15,34)$. In contrast to Reyes-Herrera et al. (28), we observed only small differences between the enrofloxacin concentrations in the breast and thigh muscles. This discrepancy may be due to differences in the applied doses. Enrofloxacin and ciprofloxacin were present at constant levels in all analysed tissue samples over a period of three consecutive days. Our results revealed that the trace enrofloxacin in the drinking water provided to the broilers during the entire breeding period significantly raised the residue concentrations of intentionally applied doxycycline in the tissues. The presence of enrofloxacin in the experimental system resulted in an approximate $50 \%$ increase in the doxycycline tissue concentration (group II) relative to group I. In the present study, doxycycline residues were also present in the tissues after five days, and we examined the concentrations on the sixth and seventh days because the WT used in experimental veterinary medicine is set at six days. This WT may be sanctioned because enrofloxacin can inhibit the activities of hepatic enzymes that are responsible for the metabolism of some medicines. The inhibition of enzymes occurs more frequently than their induction. Inhibition largely depends on genetic differences which exist between animal species. Induction or inhibition of the enzymes occurs following per os administration because all compounds must pass through the liver before reaching the circulation $(1,23)$. Enrofloxacin can inhibit the activities of cytochromes P450 and can therefore interact with the elimination of other concomitantly applied drugs (12, 33). Studies performed with dogs have demonstrated that enrofloxacin can significantly modify the metabolic processing of theophylline and result in increased theophylline concentrations in the plasma (20). Enrofloxacin can interfere with digoxin metabolism (24) and result in severe toxicosis symptoms (arrhythmia, tachycardia, and convulsions). In dogs, the elimination of anti-inflammatory medicines is slowed following the co-administration of flunixin and enrofloxacin (25). El-Gendi et al. (11) proved that in broiler chickens that have consumed feed with diclazuril and halofuginone, the injection of doxycycline results in significantly elevated doxycycline residue levels in their tissues.

The interaction between doxycycline which is intentionally administered at therapeutic doses and trace amounts of enrofloxacin in water resulted in increased doxycycline concentrations in tissues.

In our experiment, the concentrations of doxycycline did not exceed the MRL values in any of the detected matrices in either of the experimental groups of animals. However, we proved that the constant exposure of chickens to even trace amounts of enrofloxacin prior to doxycycline administration induced significant rises in tissue residue levels. Were the experiment to be repeated, any alterations in the experimental system, doses, failure of WT, or infection could exert considerable influence on the results.

This problem has very important health and economic consequences because products of animal origin with high concentrations of antibiotic residues are not approved for human consumption and have to be eliminated from the market. The unintentional exposure of breeding animals to these compounds may lead to antimicrobial resistance in animal and environmental pathogens.

Conflict of Interests Statement: The authors declare that there is no conflict of interests regarding the publication of this article.

Financial Disclosure Statement: This work was financially supported by the Ministry of Science and Higher Education (NCN Project No. DEC2013/11/N/NZ7/00434).

Animal Rights Statement: The experiments on animals were conducted with the approval of the Local Ethical Committee in Lublin.

\section{References}

1. Anadon A., Martinez-Larranaga M.R., Martinez M.A.: Drug interactions and clinical out-comes. J Vet Pharmacol Ther 2003, 26 (Suppl. 1), 22-24.

2. Atef M., Youssef S.A., El-Eanna H.A., El-Maaz A.A.: Influence of aflatoxin $\mathrm{B} 1$ on the kinetic disposition, systemic bioavailability and tissues residues of doxycycline in chickens. Br Poult Sci 2002, 43, 528-532.

3. Blondeau J.M.: Fluoroquinolones: mechanism of action, classification, and development of resistance. Surv Ophthalmol 2004, 49 (Suppl. 2), 73-78.

4. Błądek T., Posyniak A., Gajda A., Gbylik M., Żmudzki J.: Multiclass procedure for analysis of antibacterial compounds in animal tissues by liquid chromatography-tandem mass spectrometry. Bull Vet Inst Pulawy 2011, 55, 741-748.

5. Castanon J.I.R.: History of the use of antibiotic as growth promoters in European poultry feeds. Poultry Sci 2007, 86, 2466-2471.

6. Commission Decision 2002/657/EC of August 2002 implementing Council Directive 96/23/EC concerning the performance of analytical methods and the interpretation of results. Official Publications of the European Communities 2002, L 221, 8-36.

7. Commission Regulation (EU) No 37/2010 of 22 December 2009 on pharmacologically active substances and their classification regarding maximum residue limits in foodstuffs of animal origin. L15, 1-72.

8. Croubels S., Vermeersch H., De-Backer P., Santos M.D., Remon J.P., Van Peteghem C.: Liquid chromatographic separation of doxycycline and 4-epidoxycycline in a tissue depletion study of doxycycline in turkeys. J Chromatogr B Biomed Sci Appl 1998, 708, 145-152.

9. Cunha B.A., Sibley C.M., Ristuccia A.M.: Doxycycline. Ther Drug Monit 1982, 4, 115-135.

10. De Ruyck H., De Ridder H., Van Renterghem R., Van Wambeke F.: Validation of HPLC method of analysis of 
tetracycline residues in eggs and broiler meat and its application to a feeding trial. Food Addit Contam Part A 1999, 16, 47-56.

11. El-Gendi A.Y., Atef M., Amer A.M., Kamel G.M.: Pharmacokinetic and tissue distribution of doxycycline in broiler chickens pretreated with either: diclazuril or halofuginon. Food Chem Toxicol 2010, 48, 3209-3214.

12. Ershov E., Bellaiche M., Hanji V., Soback S., Gips M., Shlosberg A.: Interaction of fluoroquinolones and certain ionophores in broilers: effect on blood levels and hepatic cytochrome P450 monooxygenase activity. Drug Metabol Drug Interact 2001, 18, 209-219.

13. European Union 2014. Prospects for EU Agricultural markets and income 2014-2024 December 2014, report: http://ec.europa.eu/agriculture/markets-and-prices/medium-termoutlook/index_en.htm.

14. Gajda A., Posyniak A.: Doxycycline depletion and residues in eggs after oral administration to laying hens. Food Addit and Contam Part A 2015, 32, 1116-1123.

15. Gajda A., Posyniak A., Tomczyk G.: LC-MS/MS analysis of doxycycline residues in chicken tissues after oral administration. Bull Vet Inst Pulawy 2014, 58, 573-579.

16. Gbylik M., Posyniak A., Mitrowska K., Bladek T., Zmudzki J.: Multiresidue determination of antibiotics in fish samples by liquid chromatography - tandem mass spectrometry. Food Addit Contam Part A 2013, 30, 940-948.

17. Gbylik-Sikorska M., Posyniak A., Sniegocki T., Żmudzki J.: Liquid chromatography-tandem mass spectrometry multiclass method for the determination of antibiotics residues in water samples from water supply systems in food-producing animal farms. Chemosphere 2015, 119, 8-15.

18. Gillum J.G., Israel D.S., Polk R.E.: Pharmacokinetic drug interactions with antibacterial agents. Clin Pharmacokinet 1993, $25,450-482$

19. Holmes N.E., Charles P.G.: Safety and efficacy review of doxycycline. Clin Med Ther 2009, 1, 471-482.

20. Intorre L., Mengozzi G., Maccheroni M., Bertini S., Soldani G.: Enrofloxacin-theophylline interaction: influence of enrofloxacin on theophylline steady-state pharmacokinetics in the beagle dog. J Vet Pharmacol Ther 1995, 18, 352-356.

21. Kennedy D.G., Cannavan A., McCracken R.J.: Regulatory problems caused by contamination, a frequently overlooked cause of veterinary drug residues. J Chromatogr A 2000, 882, 37-52.

22. Landoni M.F., Albarellos G.: The use of antimicrobial agents in broiler chickens. Vet J 2015, 205, 21-27.
23. Nebbia C.: Inhibition of xenobiotic-metabolizing enzymes in veterinary species. J Vet Pharmacol Ther 2003, 26 (Suppl. 1), 19-21.

24. Novotny M.J., Shaw D.H.: Effect of enrofloxacin on digoxin clearance and steady-state serum concentrations in dogs. Can J Vet Res 1991, 55, 113-116.

25. Ogino T., Mizuno Y., Ogata T., Takahashi Y.: Pharmacokinetic interactions of flunixin meglumine and enrofloxacin in dogs. Am J Vet Res 2005, 66, 1209-1213.

26. Rantala M., Kaartinen L., Valimaki E., Stryrman M., Hiekkaranta M., Niemi A., Saari L., Piorala S.: Efficacy and pharmacokinetics of enrofloxacin and flunixin meglumine for treatment of cows with experimentally induced Escherichia coli mastitis. J Vet Pharmacol Ther 2002, 25, 251-258.

27. Rapid Alert System for Food and Feed (RASFF) Portal: https://webgate.ec.europa.eu/rasff-window/portal/?event = search ResultList. Accessed December 2015.

28. Reyes-Herrera I., Schneider M.J., Blore P.J., Donoghue D.J.: The relationship between blood and muscle samples to monitor for residues of the antibiotic enrofloxacin in chickens. Poultry Sci 2011, 90, 481-485.

29. Santos M.D., Vermeersch H., Remon J.P., Schelkens M., De Backer P., Ducatelle R., Haesebrouck F.: Validation of a high-performance liquid chromatographic method for the determination of doxycycline in turkey plasma. J Chromatogr B 1996, 682, 301-308.

30. Stahlmann R.: Clinical toxicological aspects of fluoroquinolones. Toxicol Lett 2002, 127, 269-277.

31. Surehkumar V., Venkateswaran K.V., Jayasundar S.: Interaction between enrofloxacin and monensin in broiler chickens. Vet Hum Toxicol 2004, 46, 242-245.

32. Tzivara A., Papatsiros V.G., Katsoudas V., Dritsa L., Katsoulos P.D., Evaggelidou M., Aravidou E., Christodoulopoulos G.: Residues depletion study and withdrawal period determination of sulphadiazine and trimethoprim premix in pigs. Am J Anim Vet Sci 2013, 8, 37-44.

33. Vancutsem P.M., Babish J.G.: In vitro and in vivo study of the effects of enrofloxacin on hepatic cytochrome P-450. Potential for drug interactions. Vet Human Toxicol 1996, 38, 254-259.

34. Vandenberge V., Delezie E., Huyghebaert G., Delahaut P., Daeseleire E., Croubels S.: Residues of sulfadiazine and doxycycline in broiler liver and muscle tissue due to crosscontamination of feed. Food Addit Contam Part A 2012, 29, 180-188.

35. Walker R.C.: The fluoroquinolones. Mayo Clin Proc 1999, 74, 1030-1037. 